\title{
Lysobacter enzymogenes Employs Diverse Genes for Inhibiting Hypha Growth and Spore Germination of Soybean Fungal Pathogens
}

\author{
Menghao Yu, ${ }^{1}$ Guiying Zhang, ${ }^{2}$ Jiasong Jiang, ${ }^{3}$ Liangcheng Du, ${ }^{3}$ and Youfu Zhao ${ }^{1, \dagger}$ \\ ${ }^{1}$ Department of Crop Sciences, University of Illinois at Urbana-Champaign, Urbana, IL 61801, U.S.A. \\ 2 Department of Plant Protection, College of Agriculture, Guangxi University, Nanning, Guangxi 530004, People's Republic of China \\ ${ }^{3}$ Department of Chemistry, University of Nebraska, Lincoln, NE 68588, U.S.A. \\ Accepted for publication 25 November 2019.
}

\begin{abstract}
Lysobacter enzymogenes strain $\mathrm{C} 3$ (LeC3) is a potential biocontrol agent for plant diseases caused by fungi and oomycetes. Understanding the interaction between $\mathrm{LeC} 3$ and soybean pathogens at the molecular level could help improve its biocontrol efficacy. In this study, we obtained mutants with decreased abilities in inhibiting hypha growth of the white mold pathogen Sclerotinia sclerotiorum. Insertion sites for 50 mutants, which no longer inhibited S. sclerotiorum hypha growth in dual cultural assay, were determined and seven mutants were selected for further characterization. These seven mutants also completely lost their abilities in suppressing spore germination of Fusarium virguliforme, the causal agent of soybean sudden death syndrome. Furthermore, mutation of the seven genes, which encode
\end{abstract}

ABSTRACT diguanylate cyclase, transcriptional regulators from the TetR family, hemolysin III family channel protein, type IV secretion system VirB10 protein, phenol hydroxylase, and phosphoadenosine phosphosulfate reductase, respectively, led to reduced production or secretion of four extracellular enzymes and heat-stable antifungal factor (HSAF). These results suggest that these seven genes play important roles in L. enzymogenes in suppressing hypha growth and spore germination of fungal pathogens, probably by influencing production or secretion of extracellular enzymes and HSAF.

Keywords: bacteriology, biocontrol, c-di-GMP, genetics and resistance, molecular mechanism, type 4 secretion system
Soybean (Glycine max), an important protein and oil provider, is crucial in global food security (Ainsworth et al. 2012). As the world's biggest soybean exporter, the United States produced about 4.6 billion bushels of soybean, valued at $\$ 39$ billion, in 2018 (SoyStats 2019, http://soystats.com/). Despite the increased acreage and yield, yield losses caused by soybean diseases can be tremendous. It was estimated that plant diseases reduced U.S. soybean yield by about 495 million bushels, approximately $12.5 \%$ of the 2014 annual yield and valued at about $\$ 5$ billion (http:// extension.cropsciences.illinois.edu/fieldcrops/diseases/, estimates of soybean yield reductions caused by diseases in the United States). Sclerotinia stem rot (SSR) and sudden death syndrome (SDS) are two of the five most damaging soybean diseases, leading to 37- and 68-million-bushel soybean losses in the United States in 2014, respectively. SSR (white mold) is a stem disease caused by Sclerotinia sclerotiorum, whereas the causal agent of SDS is the soilborne fungus Fusarium virguliforme ( $F$. solani f. sp. glycines) (Hartman et al. 2015; Smith and Boland 1989). Integrated management for SSR and SDS includes selection of resistant varieties, nonhost crop rotation, modest tillage, canopy management, fungicide, and biological controls, as well as delayed planting date and control of soybean cyst nematode (Mueller et al. 2016). However, crop rotation with corn is not effective for SDS because $F$. virguliforme can be harbored in corn residue, resulting in SDS

†Corresponding author: Y. Zhao; zhao888@illinois.edu

Funding: This project was supported by the North Central Soybean Research Program (NCSRP) and the China Scholarship Council.

Menghao Yu and Guiying Zhang contributed equally to this work.

*The $\boldsymbol{e}$-Xtra logo stands for "electronic extra" and indicates that one supplementary table is published online.

The author(s) declare no conflict of interest.

(c) 2020 The American Phytopathological Society outbreaks even after several years of continuous corn planting (Mueller et al. 2016).

Fungicide application is one of the most common diseasecontrolling methods, but the emergence of pathogen resistance has diminished its efficacy (Brent and Hollomon 1998). To date, fungicide resistance has been reported across a wide range of fungal pathogens, including Fusarium, Sclerotinia, Verticillium, Penicillium, Botrytis, Cercospora, Alternaria, Colletotrichum, Sphaerotheca, Mycosphaerella, Aspergillus, Phytophthora, Pythium, and Ustilago (Agrios 2005; Jo et al. 2008). On the other hand, most fungicides control plant diseases for their direct toxicity to pathogens by inhibiting cell wall biosynthesis, damaging cell membranes, and inactivating essential enzymes or certain proteins within target pathogens (Andersen et al. 2002; Hartman et al. 2014; Martínez-Toledo et al. 1998; Ochoa-Acuña et al. 2009; Taxvig et al. 2007; Ward et al. 2006). However, increased public concerns about residual fungicides in food and water have led to intensive efforts to develop more sustainable and environment-friendly control methods, such as biological control.

Normally, biological control involves the development of introduced antagonistic microorganisms and uses their natural antagonism to mitigate plant diseases. Previous studies summed up five widely accepted biocontrol mechanisms: mycoparasitism, antibiosis, extracellular enzymes, competition, and induced systematic resistance (Heydari and Pessarakli 2010; Narayanasamy 2013; Whipps 2001). Most commonly used biological control agents (BCAs) include Gliocladium virens, Trichoderma harzianum, Agrobacterium radiobacter K-84, Pseudomonas fluorescens, and Bacillus subtilis (Agrios 2005). In recent years, some gram-negative bacteria from the genus Lysobacter have emerged as novel BCAs against plant diseases (Wang et al. 2013). The Lysobacter species are ubiquitous in soil, aquatic environments, and some extreme conditions including hydrothermal vents, volcanic ash, tar pits, and compost sludge (Christensen and Cook 1978; Reichenbach 2006; Sullivan et al. 2003). Lysobacter sp. belongs to the family Xanthomonadaceae and was first proposed by Christensen and Cook in 1978 (de Bruijn et al. 2015; Hayward et al. 2010; Reichenbach 
2006). Lysobacter was first noted as a source of lytic enzymes with biodegradation abilities in organic matter recycling (Tigerstrom 1980). In the late 1990s, it emerged as novel BCA against many plant diseases (Koenning and Wrather 2010; Wang et al. 2013).

Lysobacter enzymogenes strain C3 (LeC3), which was first isolated from Kentucky bluegrass foliage in Nebraska in 1998, suppresses brown patch (Rhizoctonia solani Kuhn) (Giesler and Yuen 1998) and leaf spot (Bipolaris sorokiniana) on tall fescue (Zhang and Yuen 1999), Pythium damping-off of sugar beet (Palumbo et al. 2005), bean rust (Uromyces appendiculatus) (Yuen et al. 2001), Fusarium head blight of wheat (Fusarium graminearum) (Jochum et al. 2006), sugar beet cyst nematode (Heterodera schachtii), root-knot nematode (Meloidogyne javanica), and root lesion nematode (Pratylenchus penetrans) (Chen et al. 2006). Previous research confirmed the broadspectrum activities of LeC3 in suppressing hypha growth and spore germination of eight fungal or oomycete pathogens on soybeans, including $S$. sclerotiorum, $R$. solani, $F$. virguliforme, Cerocospora sojina, Macrophomina phaseolina, Phytophthora sojae, Pythium sylvaticum, and Septoria glycines (Nian 2015). In LeC3, genes for antibiotics and extracellular enzymes, such as chitinase, $\beta-1,3-$ glucanase, heat-stable antifungal factor (HSAF, a broad-spectrum antifungal antibiotic), and WAP-8294A2, have been identified and characterized (Palumbo et al. 2005; Qian et al. 2012; Yu et al. 2006; Zhang et al. 2011). Moreover, regulatory systems in L. enzymogenes, including the Clp global regulator and quorum sensing systems mediated by diffusible signal factors or diffusible factors, were found to be involved in the modulation of its biocontrol-related characteristics (Chen et al. 2018; Kobayashi et al. 2005; Qian et al. 2013). The purpose of our study is to further identify and characterize novel genes involved in biocontrol activities of LeC3 in suppressing hypha growth and spore germination of important fungal pathogens of soybean.

\section{MATERIALS AND METHODS}

Bacterial strains and growth conditions. Bacterial strains and plasmids used in this study are listed in Table 1. Escherichia coli strain DH10 $\beta$, used for plasmid construction, was routinely grown in Luria-Bertani (LB) medium at $37^{\circ} \mathrm{C}$. Tryptic soy medium $(10 \%$ trypticase soy broth, $1.5 \mathrm{~g} /$ liter of tryptone, $0.5 \mathrm{~g} /$ liter of soytone, and $0.5 \mathrm{~g}$ /liter of $\mathrm{NaCl}$ ) was used for culturing $\mathrm{LeC} 3$ and its derived strains at $28^{\circ} \mathrm{C}$ ( $\mathrm{Yu}$ and Zhao 2019). Antibiotics were used as required at the following concentrations unless otherwise noted: gentamicin at $30 \mu \mathrm{g} / \mathrm{ml}$ and kanamycin $(\mathrm{Km})$ at $100 \mu \mathrm{g} / \mathrm{ml}$. Primers used in this study for inverse PCR, mutant confirmation, cloning, and sequencing are listed in Supplementary Table S1.

Dual culture assay. Dual cultural assay was used to determine the inhibition of $S$. sclerotiorum hypha growth by LeC3 and its derivative strains, as described previously (Nian 2015). In brief, 5-mm-diameter discs of fresh-grown S. sclerotiorum BF0934, originally obtained from Dr. Carl Bradley's lab at University of Illinois, were placed in the center of $25 \%$ potato dextrose agar (PDA) or $10 \%$ trypticase soy agar plate. Bacterial suspensions $(5 \mu \mathrm{l}$, $\mathrm{OD}_{600}=0.2$ unless otherwise noted) were pipetted into the same plate about $2.5 \mathrm{~cm}$ away from the fungal disc. After incubation at $28^{\circ} \mathrm{C}$, fungal hyphae reached plate edges, and the diameters of inhibition zones around LeC 3 or its derived mutants were measured. The experiments were repeated at least twice in triplicate.

Construction of L. enzymogenes transposon (Tn) mutant library and identification of Tn insertion sites. A transposon mutagenesis kit was used for random mutagenesis according to the manufacturer's instructions. Briefly, to prepare competent cells, an overnight bacterial culture was subcultured to exponential phase in LB amended with $\mathrm{Km}$. Cells were then harvested, washed with cold sterile water, and transformed with $1 \mu$ of transposome by electroporation. After $3 \mathrm{~h}$ of incubation at $28^{\circ} \mathrm{C}$, transformants were plated on LB amended with $2,000 \mu \mathrm{g} / \mathrm{ml} \mathrm{Km}$ (Yu and Zhao 2019). A total of 948 colonies was picked and screened via dual culture assay. Mutants with reduced inhibition zones were selected and stored at $-80^{\circ} \mathrm{C}$.

Inverse PCR or random amplification of transposon ends (RATE) PCR was used to determine Tn5 insertion site. Inverse PCR was performed as previously described (Lee et al. 2018). Briefly,

TABLE 1. Bacterial strains and plasmids used in this study

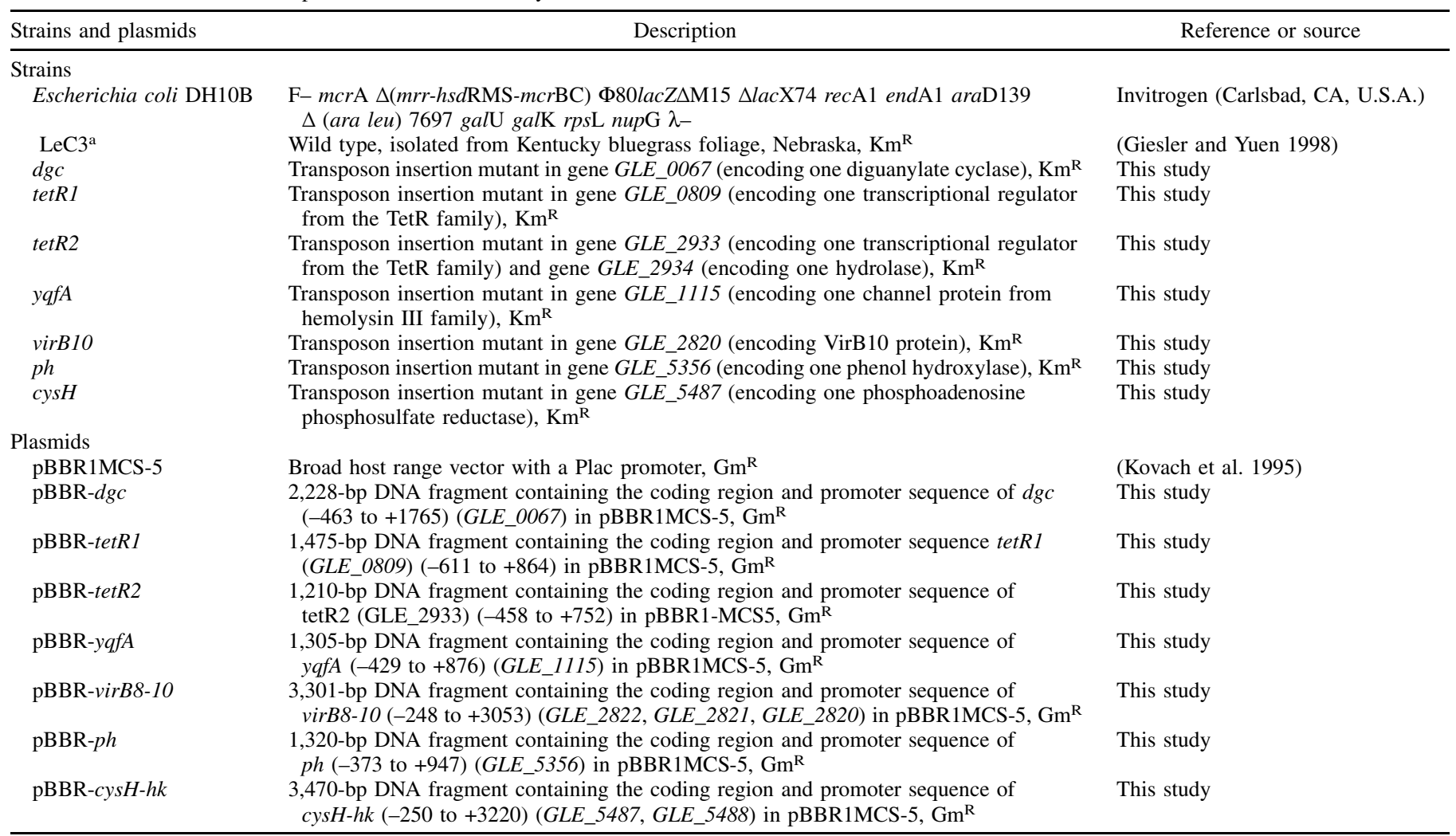

${ }^{a}$ LeC3, Lysobacter enzymogenes strain C3, genome sequence GenBank accession number CP013140. 
genomic DNA of overnight bacterial cultures was isolated with a DNA and RNA purification kit, digested with a restriction enzyme (PstI or $P v u \mathrm{I})$, and ligated with T4 DNA ligase. For PCR, DNA samples treated with PstI were amplified with the primer pair KAN-2 FP-1/KAN-2 RP-1, whereas DNA samples treated with $P v u$ I were amplified with the primer pair KAN-2 FP1/PvuI-right or KAN-2 RP1/PvuI-left (Supplementary Table S1). RATE procedure was used as an alternative method to determine the insertion sites for mutants when inverse PCR failed (Clavijo et al. 2006). It is a three-step PCR performed with single primer inv-1 or inv-2, as listed in Supplementary Table S1. The first and third steps used stringent annealing temperature, and the second step used $30^{\circ} \mathrm{C}$, which allowed nonspecific amplification (Ducey and Dyer 2002). PCR products from both inverse and RATE PCR were then gel purified and sequenced at the University of Illinois at UrbanaChampaign core sequencing facility. The flanking sequences of the transposon insertion site were analyzed via BLAST search at NCBI. PCR was then performed to confirm the insertion sites with the primers listed in Supplementary Table S1.
Complementation of mutants. A plasmid-based method was used to complement selected mutants as described previously (Qian et al. 2013). Briefly, DNA fragments containing full-length selected genes and their corresponding promoter regions were amplified by PCR with a pair of primers (Supplementary Table S1). Purified PCR products were cloned into pBBR1MCS-5 (Kovach et al. 1995). After confirmed by DNA sequencing with primers M13For-40 and M13Rev-48 (Supplementary Table S1), the final plasmids were electroporated into the corresponding mutants, and the transformants were verified by PCR.

Spore germination assay. $F$. virguliforme Mont-1 isolate was originally obtained from Dr. Glen L. Hartman's laboratory at the University of Illinois. Fungal spores were harvested by washing from PDA plates 7 days postinoculation (DPI) at $28^{\circ} \mathrm{C}$. Spore concentration was counted by hemocytometer and adjusted to $2 \times 10^{5}$ per milliliter in $25 \%$ potato dextrose broth. Supernatant of 3 -day-old bacterial cultures was prepared by centrifugation at $13,200 \mathrm{rpm}$ for $20 \mathrm{~min}$. Equal volumes $(1 \mathrm{ml}$ each) of spore

TABLE 2. List of 50 mutants with no inhibition zone in suppressing Sclerotinia sclerotiorum ${ }^{\mathrm{a}}$

\begin{tabular}{|c|c|c|c|c|}
\hline Mutant & Insertion site & Accession & Description & Gene \\
\hline 1 & 73872 & GLE_0067 & Diguanylate cyclase & $d g c$ \\
\hline 2 & 182656 & $G L E \_0173 / 4$ & NAD-dependent epimerase/dehydratase family protein and hypothetical protein & \\
\hline 3 & 284302 & $G L E \_0261 / 2$ & Hypothetical protein and anhydro-N-acetylmuramic acid kinase & anmK \\
\hline 4 & 299631 & GLE_0270 & Peptidase & \\
\hline 5 & 320871 & GLE_0290 & Cytochrome c oxidase, subunit III & $\operatorname{ccoP}$ \\
\hline 6 & 384565 & GLE_0349 & DNA topoisomerase I & topA \\
\hline 7 & 474196 & GLE_0432 & Type VI secretion-associated protein, BMA_A0400 & tsss \\
\hline 8 & 480652 & GLE_0436 & Type VI secretion system Vgr family protein & $v g r$ \\
\hline 9 & 750857 & GLE_0688/9 & ATP synthase F1, gamma subunit, and ATP synthase F1, beta subunit & atp $G$ and $a t p D$ \\
\hline 10 & 796945 & $G L E \_0724$ & Hypothetical protein & \\
\hline 11 & 870633 & GLE_0794 & Hypothetical protein & \\
\hline 12 & 883488 & GLE_0809 & Transcriptional regulator, TetR family & tetR1 \\
\hline 13 & 995287 & GLE_0899 & Hypothetical protein & \\
\hline 14 & 1122532 & $G L E \_1022$ & Ribosomal protein S6 modification protein & \\
\hline 15 & 1223320 & $G L E \_1115$ & Channel protein, hemolysin III family & $y q f A$ \\
\hline 16 & 1339631 & $G L E \_1223 / 4$ & DnaA regulatory inactivator $\mathrm{Hda}$ and hypothetical protein & \\
\hline 17 & 1900985 & $G L E \_1773 / 4$ & Rhs family protein and hypothetical protein & \\
\hline 18 & 2305361 & $G L E \_2122$ & Transcriptional regulator, ArsR family & \\
\hline 19 & 2597971 & $G L E \_2373 / 4$ & Exported SurF1-family protein and cytochrome o ubiquinol oxidase subunit IV & cyoD \\
\hline 20 & 2622226 & $G L E \_2396$ & Transcriptional regulator, Rrf2 family & \\
\hline 21 & 3187974 & $G L E \_2820$ & VirB10 protein & $\operatorname{virB10}$ \\
\hline 22 & 3189337 & $G L E \_2821$ & VirB9 protein & virB9 \\
\hline 23 & 3201951 & $G L E \_2836$ & Homoserine O-acetyltransferase & $m e t X$ \\
\hline 24 & 3238729 & $G L E \_2875$ & Hypothetical protein & \\
\hline 25 & 3296438 & $G L E \_2933 / 4$ & Transcriptional regulator, TetR family, and hydrolase & tetR2 \\
\hline 26 & 3590009 & $G L E \_3215$ & HSAF nonribosomal peptide synthetase/polyketide synthase & hsaf pks-nrps \\
\hline 27 & 3592591 & $G L E \_3215$ & HSAF nonribosomal peptide synthetase/polyketide synthase & hsaf pks-nrps \\
\hline 28 & 3996196 & $G L E \_3585$ & Multiple antibiotic resistance & mar \\
\hline 29 & 4744813 & $G L E \_4202$ & Prolyl-tRNA synthetase & proS \\
\hline 30 & 4833742 & $G L E \_4286 / 7$ & Diacylglcerol kinase catalytic domain and RraA family & \\
\hline 31 & 5066843 & $G L E \_4519$ & Leukotriene A-4 hydrolase & lta $4 h$ \\
\hline 32 & 5158558 & $G L E \_4600$ & Hypothetical protein & \\
\hline 33 & 5505166 & $G L E \_4939 / 40$ & Coproporphyrinogen III oxidase, aerobic, and DNA polymerase I & hemF and polA \\
\hline 34 & 5688480 & $G L E \_5096$ & Transporter, major facilitator family & \\
\hline 35 & 5787442 & $G L E \_5193$ & Glucose-6-phosphate 1-dehydrogenase & $z w f$ \\
\hline 36 & 5917666 & GLE_5315 & Hypothetical protein & \\
\hline 37 & 5942260 & $G L E \_5338 / 9$ & DNA polymerase III, beta subunit, and chromosomal replication initiator protein & $\operatorname{dnaN}$ and $\operatorname{dnaA}$ \\
\hline 38 & 5960481 & $G L E \_5356$ & Phenol hydroxylase & ph \\
\hline 39 & 5995668 & $G L E \_5394$ & Lipoprotein & \\
\hline 40 & 6028676 & $G L E \_5430$ & Lipoprotein & \\
\hline 41 & 6087030 & $G L E \_5486$ & Hypothetical protein & \\
\hline 42 & 6087195 & GLE_5486 & Hypothetical protein & \\
\hline 43 & 6088863 & $G L E \_5486$ & Hypothetical protein & \\
\hline 44 & 6088893 & $G L E \_5486$ & Hypothetical protein & \\
\hline 45 & 6089229 & $G L E \_5486$ & Hypothetical protein & \\
\hline 46 & 6089509 & $G L E \_5486 / 7$ & Hypothetical protein and phosphoadenosine phosphosulfate reductase & cys $H$ \\
\hline 47 & 6089556 & $G L E \_5486 / 7$ & Hypothetical protein and phosphoadenosine phosphosulfate reductase & cys $H$ \\
\hline 48 & 6089719 & $G L E \_5487$ & Phosphoadenosine phosphosulfate reductase & cys $H$ \\
\hline 49 & 6090763 & $G L E \_5488$ & Histidine kinase family protein & $h k$ \\
\hline 50 & 6139312 & $G L E \_5537 / 8$ & Hypothetical protein and hypothetical protein & \\
\hline
\end{tabular}

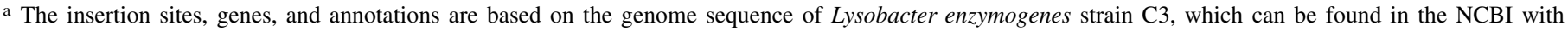
GenBank accession number CP013140. 
suspension and bacterial culture supernatant were mixed in 14-ml round-bottom Falcon tubes, vortexed, and then placed in an incubator with shaking at $200 \mathrm{rpm}$ at $25^{\circ} \mathrm{C}$. Sixteen hours after cocultivation, $15 \mu \mathrm{l}$ of each mixture was pipetted onto $25 \%$ PDA plates and incubated at $28^{\circ} \mathrm{C}$ for 3 and half days. Meanwhile, $10 \mu \mathrm{l}$ of each mixture was pipetted into a hemocytometer and germination examined under a microscope. A spore was considered germinated only if its germ tube was at least the length of the spore. The experiment was repeated twice with three replicates.

Extracellular enzyme activity assays. To determine extracellular activities of protease, cellulase, lipase, and chitinase, $3 \mu \mathrm{l}$ of bacterial culture adjusted to $\mathrm{OD}_{600}=1$ was respectively spotted on LB plates containing $1 \%$ (mass/vol) skim milk, Van Niel medium $\left(1 \mathrm{~g} /\right.$ liter of yeast extract, $0.25 \mathrm{~g} /$ liter of $\mathrm{MgSO}_{4}$, and $20 \mathrm{~g} / \mathrm{liter}$ of agar) plates containing $1.5 \%$ (mass/vol) carboxymethyl cellulose, basal agar medium ( $10 \mathrm{~g} /$ liter of peptone, $15 \mathrm{~g} /$ liter of agar, and 0.26 $\mathrm{g} /$ liter of $\mathrm{CaCl}_{2} \cdot 2 \mathrm{H}_{2} \mathrm{O}$ ) plates containing $1 \%$ (vol/vol) Tween 80 , and $2 \%$ (mass/vol) agar plates containing $0.5 \%$ (mass/vol) colloidal chitin, at $28^{\circ} \mathrm{C}$. For protease activity, diameters of hydrolytic zones surrounding bacterial colonies were measured at one and half DPI. For cellulase activity, plates were stained with $0.1 \%$ (mass/vol) Congo red for $30 \mathrm{~min}$ at 3 DPI to display hydrolytic zones. For lipase activity, diameters of calcium soap circles surrounding bacterial colonies were measured at 3 DPI. Colloidal chitin used in extracellular chitinase activity assay was prepared from crude chitin as described previously, with minor modifications (Roberts and Selitrennikoff 1988). Briefly, $2.5 \mathrm{~g}$ of chitin powder from shrimp shells was completely dissolved in $45 \mathrm{ml}$ of concentrated

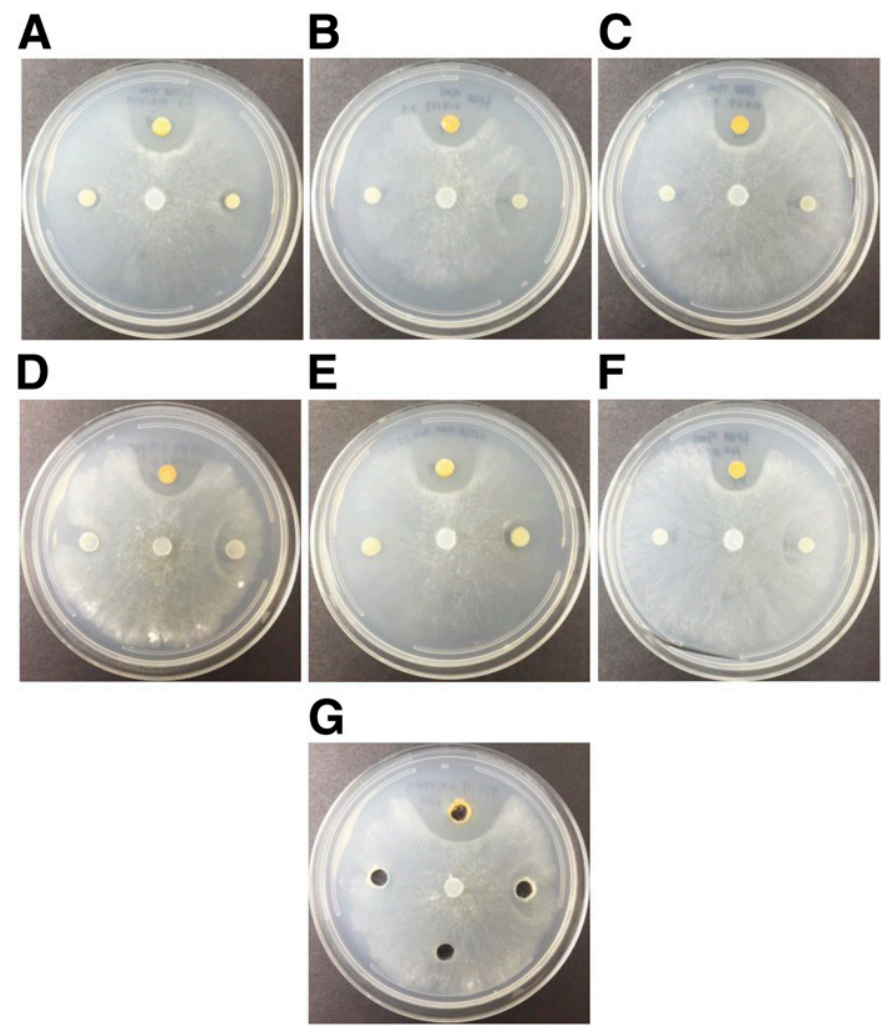

Fig. 1. Effect of Lysobacter enzymogenes mutants in inhibiting Sclerotinia sclerotiorum hypha growth. A, The $d g c$ mutant (left) and complementation (right); $\mathbf{B}$, the tetR 1 and $\mathbf{C}$, tetR2 mutant (left) and complementation (right); $\mathbf{D}$, the yqfA (left) and complementation (right); E, the virB10 (left) and complementation (right); F, the $p h$ (left) and complementation (right); and $\mathbf{G}$, the cysH (left) and complementation (right). On $10 \%$ trypticase soy agar (A and E) or $25 \%$ potato dextrose agar (B to $\mathrm{D}, \mathrm{F}, \mathrm{G}$ ) plates, $5 \mu \mathrm{l}$ of wild-type $L$. enzymogenes strain C3 (top), mutant (left), and corresponding complementation strain (right) with $\mathrm{OD}_{600}=0.2$ were cocultured with $S$. sclerotiorum, except for $\mathrm{D}, 12.5 \mu \mathrm{l}$ with $\mathrm{OD}_{600}=0.4$ and $\mathbf{G}, 100 \mu \mathrm{l}$ with $\mathrm{OD}_{600}=0.5$.
$\mathrm{HCl}$ and then transferred into $600 \mathrm{ml}$ of water. The mixture was placed at $4{ }^{\circ} \mathrm{C}$ overnight. Sample pellet was washed several times by removing water on the surface until the $\mathrm{pH}$ reached 5.5 to 6.0. After the final wash, colloidal chitin was filtered through three-layer nylon web, autoclaved, and stored at $4^{\circ} \mathrm{C}$ in dark. The experiments were repeated at least twice with three replications. Fisher's least significant difference procedure was performed via the PROC GLM option of SAS version 9.4 to compare the means of substratedegrading zone diameters.

HSAF extraction and detection. HSAF extraction was performed as described previously (Qian et al. 2014). Bacterial strains were grown in $50 \mathrm{ml}$ of $10 \%$ trypticase soy broth at $28^{\circ} \mathrm{C}$ for 3 and half days. After centrifugation at $4^{\circ} \mathrm{C}$ for $30 \mathrm{~min}, 10 \mathrm{ml}$ of supernatant was collected and vortexed with an equal volume of ethyl acetate. Then ethyl acetate phase containing HSAF was collected and completely dried at room temperature. Final HSAF extraction was resuspended in $200 \mu$ l of methanol. An HSAF sample $(20 \mu \mathrm{l})$ was injected and analyzed with a high-performance liquid chromatography (HPLC) system. The HPLC system included a degasser, an autosampler, a diode array detector, and a quaternary pump. Liquid chromatography separation was performed on a reversed phase HPLC column $(4.6 \times 150 \mathrm{~mm}, 5 \mu \mathrm{m})$ with mobile phase A $(0.1 \%$ formic acid in water $)$ and $\mathrm{B}(0.1 \%$ formic acid in acetonitrile). A modified HPLC program was performed as follows: 60 to $100 \%$ mobile phase $\mathrm{B}$ in mobile phase A from 0 to $10 \mathrm{~min}$, $100 \%$ mobile phase B from 10 to 13 min, 100 to $60 \%$ mobile phase $\mathrm{B}$ in mobile phase A from 13 to $14 \mathrm{~min}$, and $60 \%$ mobile phase B in mobile phase A from 14 to $20 \mathrm{~min}$. HSAF was detected at $318 \mathrm{~nm}$ with a UV detector. The experiments were repeated twice with similar results.

\section{RESULTS}

Identification of Tn5 mutants of LeC3 with reduced suppression of $S$. sclerotiorum hypha growth. To fully understand the molecular mechanism of LeC3 in suppressing fungal hypha growth, random insertion mutant library was screened for mutants lacking in suppressing fungal hypha growth. In total, we obtained 141 mutants with reduced abilities in inhibiting $S$. sclerotiorum hypha growth and determined the Tn5 insertion sites for 50 mutants, which exhibited no inhibition zones in dual culture assays (Table 2). These mutants included mutations in the HSAF biosynthetic gene (hsaf pks-nrps) at two locations (i.e., 3590009 and 3592591; \#26 and \#27) and genes encoding lipoproteins (\#39 and \#40) and transcriptional factors (the TetR [\#12 and \#25], ArsR [\#18], and Rrf2 [\#20] family). Several clustered genes were also found to be mutated, including genes encoding type VI secretion system (\#7 and \#8), type IV secretion system (T4SS) (\#21 and \#22), and one region (from \#41 to \#49) containing a hypothetical gene (GLE_5486), cysH (GLE_5487), and a histidine kinase (GLE_5488). These results indicated that these genes or regions may be important in inhibiting $S$. sclerotiorum hypha growth.

Depending on the functions of their predicted proteins based on the standard of Clusters of Orthologous Groups and EggNOG databases (Huerta-Cepas et al. 2015), other identified genes could be grouped into four major classes: (i) cellular processes and signaling, including diguanylate cyclase and multiple antibiotic resistance; (ii) information storage and processing, including DNA topoisomerase, ribosomal protein, and prolyl-tRNA synthetase; (iii) metabolism, including cytochrome c oxidase and phenol hydroxylase, glucose-6-phosphate dehydrogenase, leukotriene A-4 hydrolase, and homoserine $\mathrm{O}$-acetyl; and (iv) functions unknown, including peptidase, hemolysin protein, and transporter from major facilitator family (Table 2). In addition, genes for 15 mutants encode hypothetical proteins without putative functions.

For the rest of this study, we selected seven mutants for further characterization, including genes encoding TetR family transcriptional regulators (tetR1 and tetR2), diguanylate cyclase $(d g c)$, 
hemolysin III family channel protein (yqfA), type IV secretion system VirB10 protein (T4SS, virB10), phenol hydroxylase $(p h)$, and phosphoadenosine phosphosulfate reductase (cysH) (Table 1). First, we showed that complementation of the seven mutants partially restored their abilities in inhibiting S. sclerotiorum hypha growth. In a dual culture assay with $S$. sclerotiorum, clear inhibition zones were observed around LeC3 (Fig. 1A to G, top), whereas no inhibition zones were seen around the seven mutants (Fig. 1A to G, left). For complementation strains, complete or partial recovery of inhibition zones was observed, some with very clean zones ( $d g c$ and virB10, Fig. 1A and E, right), whereas others with fewer visible hyphae (Fig. 1B to D, F and G, right). These results indicate that
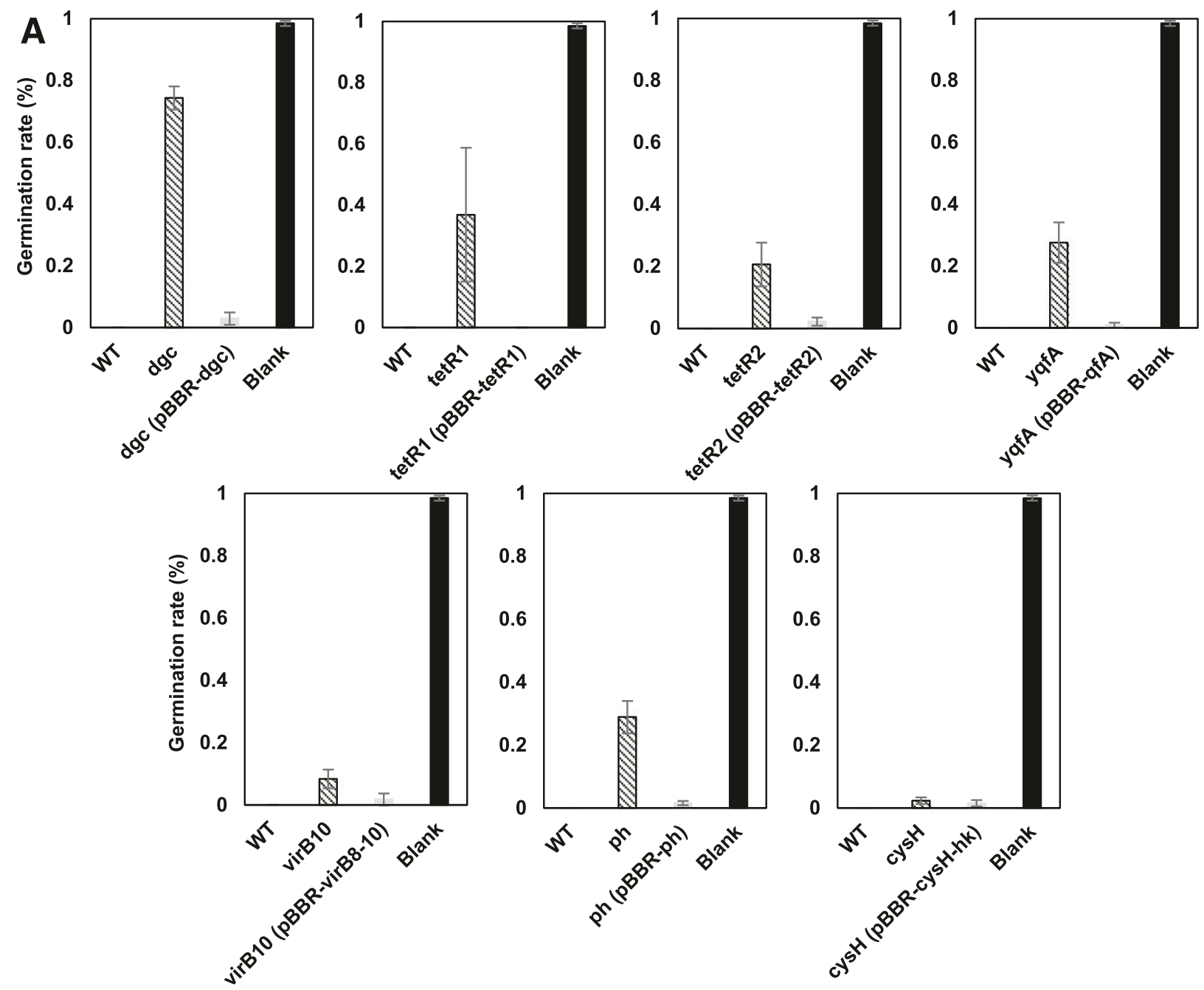

B
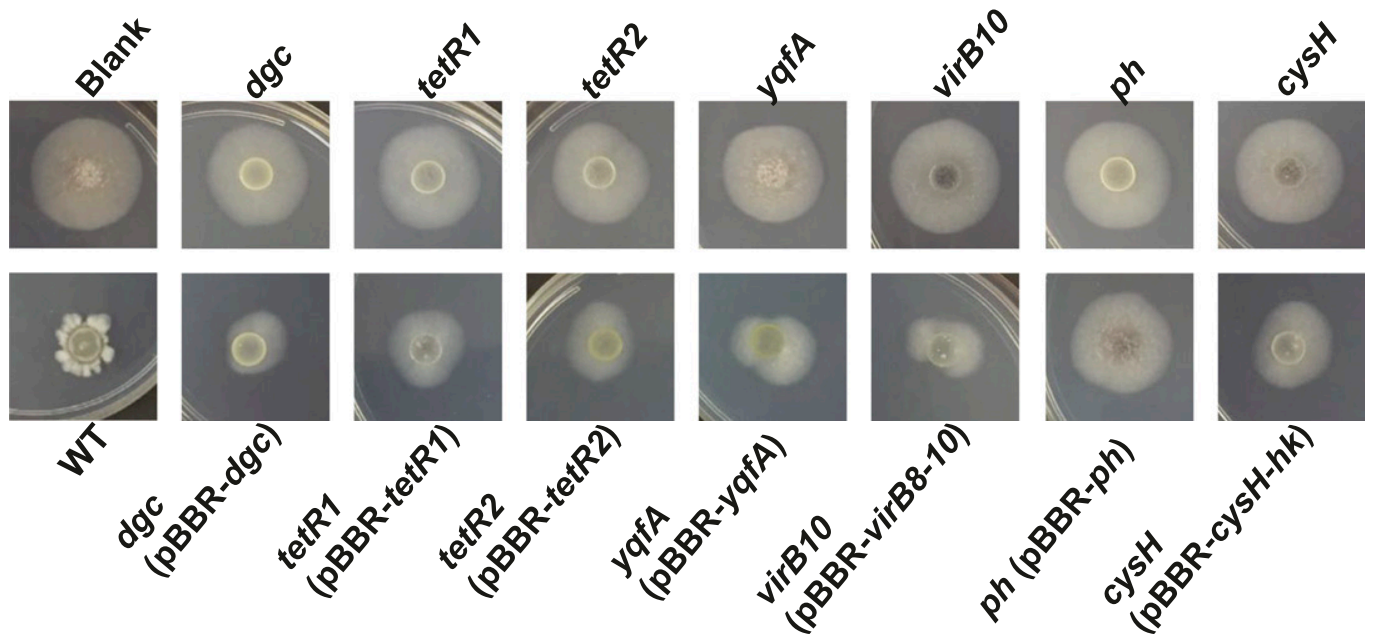

Fig. 2. Lysobacter enzymogenes mutants exhibited decreased abilities in inhibiting Fusarium virguliforme A, spore germination and B, growth. Supernatants of 3 -day-old bacterial culture were mixed with $2 \times 10^{5}$ conidia spore/ml of $F$. virguliforme overnight in a shaking incubator $(200 \mathrm{rpm})$ at $25^{\circ} \mathrm{C}$. Spore germination was examined under microscope in hemocytometer, and $15 \mu \mathrm{l}$ of each overnight mixture was pipetted onto $25 \%$ potato dextrose agar plates and incubated at $28^{\circ} \mathrm{C}$. Pictures were taken 3.5 days after inoculation. $c y s H$, the $c y s H$ mutant; $d g c$, the $\operatorname{dgc}$ mutant; $p h$, the ph mutant; tetR1 and tetR2, the tetR1 and tetR2 mutants; virB10, the virB10 mutant; WT, wild type L. enzymogenes strain C3; yqfA, the yqfA mutant. 
these genes are responsible for inhibiting S. sclerotiorum hypha growth.

Mutations of the seven genes in L. enzymogenes also led to decreased abilities in inhibiting $F$. virguliforme spore germination and growth. Under microscope, Fusarium spores mixed with LeC3 supernatant were either lysed or not germinated, making the germination rate 0 , whereas germination rate for blank control was almost 1 . In contrast, Fusarium spores mixed with supernatants of the seven mutants exhibited higher germination rates, ranging from 0.02 to 0.74 (Fig. 2A). Complementation of the seven mutants restored spore germination rate to almost 0 (Fig. 2A). In addition, growth of Fusarium spores mixed with LeC3 was severely inhibited as compared with control (Fig. 2B). Spores mixed with seven mutants grew much faster than that of LeC3, indicating that the seven mutants also decreased in their abilities in inhibiting F. virguliforme spore growth (Fig. 2B), whereas Fusarium spores mixed with complementation strains exhibited less growth (Fig. 2B). These results suggested that these seven genes are also responsible for inhibiting $F$. virguliforme spore germination and growth.

Extracellular enzyme activities were decreased in the seven mutants. To determine what contributes to the reduced activities against fungal pathogens, extracellular enzyme activities of the seven mutants were determined. Protease, cellulase, and lipase activities were significantly lower in the seven mutants than those of LeC3 (Figs. 3A to $\mathrm{C}$ and $4 \mathrm{~A}$ to $\mathrm{C}$ ). Significant differences were also observed among the seven mutants, where the cysH mutant exhibited the lowest activities. Furthermore, no hydrolytic zones around the $d g c$, virB10, and cysH mutants were observed on $2 \%$ agar plates containing $0.5 \%$ colloidal chitin, suggesting that these mutants no longer had detectable chitinase activities (Figs. 3D and 4D). Chitinase activities of the other mutants were significantly lower than that of LeC3, whereas significant differences in chitinase activities were also observed among the seven mutants, except tetR 1 mutant (Figs. 3D and 4D).

Extracellular enzyme activities in complementation strains were partially restored for most mutants, as shown in Figure 4. As an example, complementation of the virB10 mutant showed significantly higher activity of cellulase and chitinase (Fig. 5A). Complementation of the tetRl, yqfA, and $c y s H$ mutants exhibited significantly increased extracellular protease activities (Fig. 5B). Moreover, complementation of the $y q f A$, virB 10 (in LB containing $0.5 \%$ Tween 80 ), and $c y s H$ mutants exhibited significantly increased extracellular lipase activity (Fig. 5C). However, most complementation strains exhibited slightly higher enzyme activities than those of their corresponding mutants (Fig. 4). These results showed that the seven genes play a role in extracellular enzyme activities, which might contribute to antifungal activities.

HSAF was not detectable in the seven mutants. To test whether the seven genes contribute to HSAF biosynthesis, their HSAF production was determined by HPLC. As shown in Figure 6, the single HSAF peak was detected in the sample of HSAF standard and LeC3, whereas no HSAF peak was detected in the hsaf pks-nrps mutant, which was previously proven to be defective in HSAF production and serve as a negative control (Fig. 6). Interestingly,
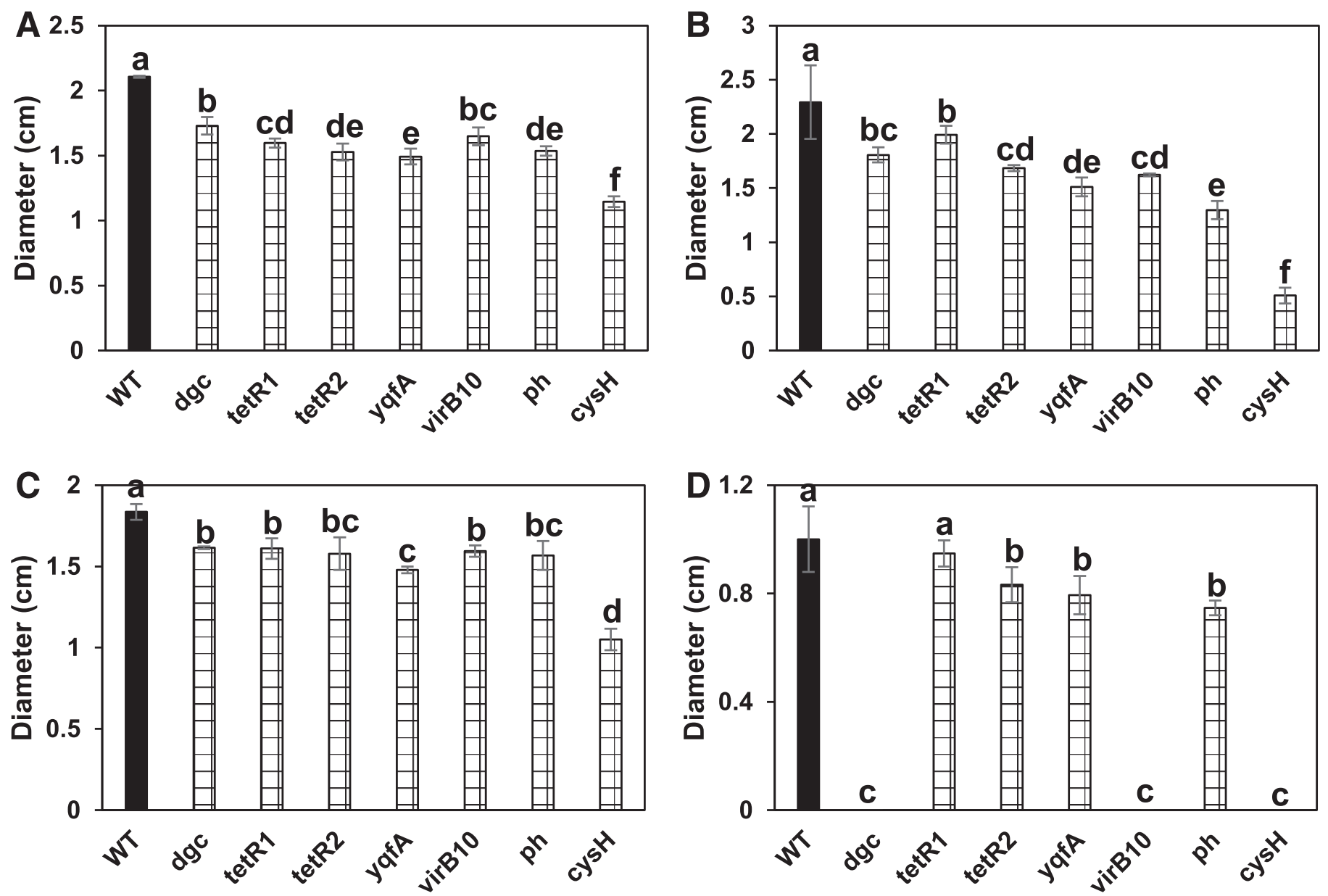

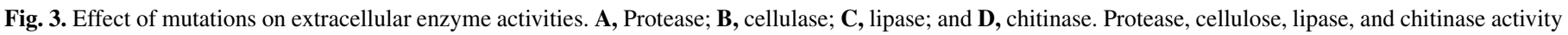

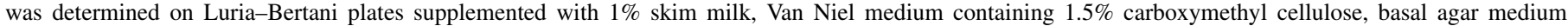

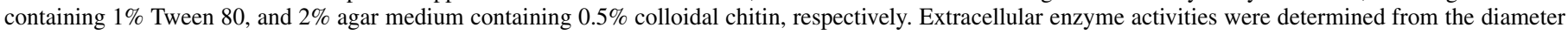

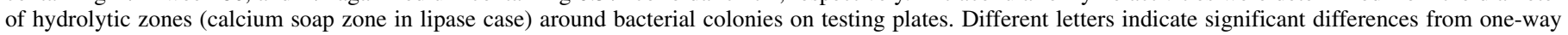

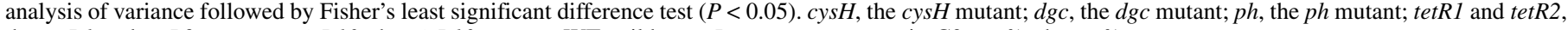
the tetR1 and tetR2 mutants; virB10, the virB10 mutant; WT, wild type L. enzymogenes strain C3; yqfA, the yqfA mutant. 
samples from all seven mutants showed no detectable HSAF. Despite multiple attempts and scale-up sample preparations, HSAF was not detectable in all seven complementation strains (data not shown). Although our results were not conclusive, these results nonetheless suggested that the seven genes might be involved in regulation of HSAF biosynthesis or secretion of HSAF in L. enzymogenes.

\section{DISCUSSION}

L. enzymogenes strains have been considered as potential BCAs, including strains N4-7, LeC3, 3.1T8, and OH11 (Folman et al. 2003; Giesler and Yuen 1998; Kobayashi and Nour 1996; Qian et al. 2009). Understanding of their interactions with fungi or other pathogens is far from complete. In this study, we obtained 50 mutants of LeC3 with no inhibition of S. sclerotiorum hypha growth, and the insertion sites for about one fourth of these mutants were located within three $4-\mathrm{Kb}$ regions, including the T4SS gene cluster, the HSAF biosynthesis gene hsafpks-nrps, and a three-gene operon, which encodes a hypothetical protein, a phosphoadenosine phosphosulfate (PAPS) reductase, and a histidine kinase family protein. These results indicated that these regions might be important in its inhibitory activities against the white mold pathogen S. sclerotiorum (Clavijo et al. 2006; Ducey and Dyer 2002; Xia et al. 2015). Previous studies revealed that mutation in the hsaf pks-nrps gene no longer inhibited fungal hypha growth, which is consistent with our results (Yu et al. 2006). It is now known that the hybrid polyketide synthase and nonribosomal peptide synthetase encoded by the hsaf pks-nrps gene catalyzes the essential step of linking ornithine to polyketides in the biosynthesis of HSAF (Lou et al. 2011). Further studies also showed that small metabolites, 4-hydroxybenzoic acid and 13-methyltetradecanoic acid, could increase the transcription of the hsaf pks-nrps gene, leading to increased HSAF production (Han et al. 2015; Su et al. 2017).

T4SSs in Gram-negative bacteria are found to have versatile functions, including conjugative transformation, mediation of genetic exchange, and delivery of macromolecular effectors (such as toxin and T-DNA) into eukaryotic cells (Fronzes et al. 2009). The Type IVA T4SSs (VirB-VirD4 conjugative system) consist of 12 proteins, i.e., VirD4 and VirB1 to VirB11. The periplasmic lytic transglycosylase VirB1 is required for pilus biogenesis and degradation of peptidoglycan layer; VirB2 and BirB5 is responsible for the formation of pilus which will extend into extracellular milieu; proteins VirB3 and VirB6 to VirB10 collectively form the scaffold and translocation apparatus; whereas VirB4, VirB11, and VirD4 are three ATPases which power T4SSs (Costa et al. 2015). The LeC3 genome harbors a virB1-11 cluster with a distantly located virD4 gene, as well as two copies of the virB5 gene and multiple pairs of the virB5-virB6 gene cluster (de Bruijn et al.2015). In this study, we identified two mutants (virB10 and virB9) located within the T4SS cluster, suggesting that T4SS in LeC3 might play an important role in suppressing fungal hypha growth. Although extracellular enzymes are normally secreted by type II secretion system, we found that the virB10 mutant exhibited significantly reduced protease, cellulase and lipase activities as well as no chitinase activity.

Insertion sites of eight mutants were within a three-gene operon, which encodes a hypothetical protein, a PAPS reductase, and a histidine kinase family protein. In E. coli, the PAPS reductase catalyzes the conversion of PAPS into sulfite and adenosine $3^{\prime}, 5^{\prime}$ bisphosphate (PAP) in the sulfate reduction pathway, which leads to the assimilation of sulfur and biosynthesis of cysteine (Rossi et al. 2014). Recent studies have revealed that other intermediates in E. coli sulfate assimilation and cysteine biosynthesis pathway (e.g., PAP, PAPS) can also act as a global signal molecule and modulate gene expression (Longo et al. 2016). Inactivation of the $c y s H$ gene increased intracellular PAPS concentration and consequently increased cell aggregation and surface adhesion by regulation over the expression of curli components, including Flu, OmpX, Slp, and other regulators CspC, CspE, HNS, and HupA (Longo et al. 2016). Because the PAPS reductase in E. coli and L. enzymogenes shares $66 \%$ deduced amino acid similarity, and immediately after the $c y s H$ gene is a gene encoding a signal transduction histidine kinase in LeC3, it is tempting to speculate that loss of inhibition of fungal hypha growth and spore germination may be caused by affecting the PAPS-mediated regulatory system in L. enzymogenes.

In Xanthomonas campestris, it has been proven that the sensor kinase RpfC detects the diffusible signal factor signal and activates the response regulator RpfG, which degrades c-di-GMP and thus activates virulence genes (Tao et al. 2010). In addition, c-di-GMP specifically interacts with the global regulator Clp, leads to the allosteric conformational changes of $\mathrm{Clp}$, and abolishes binding to
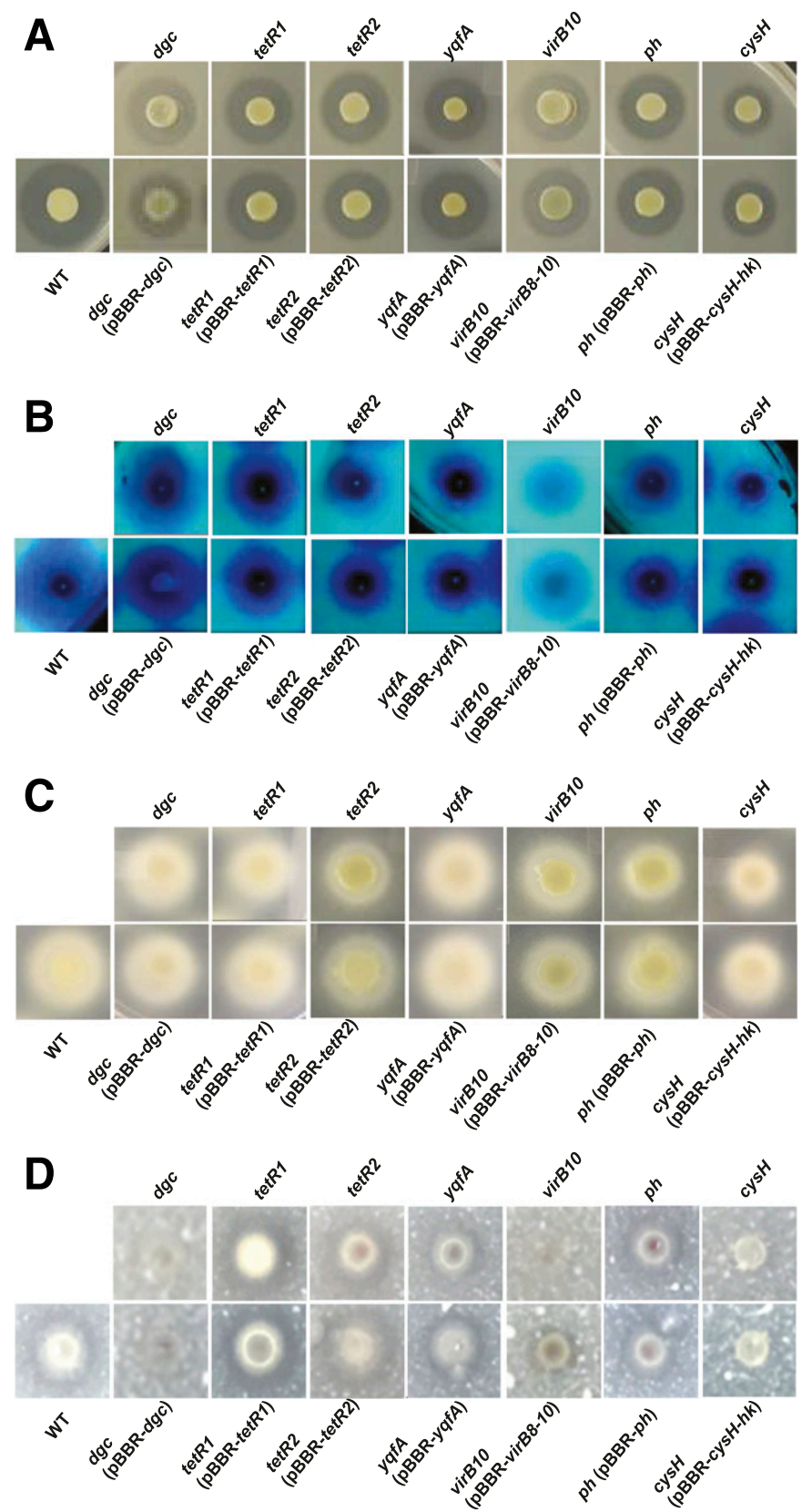

Fig. 4. Extracellular enzyme activities of Lysobacter enzymogenes strain C3, mutants, and their complementation strains. A, Protease; B, cellulase; C, lipase; and D, chitinase. Protease, cellulose, lipase, and chitinase activity was determined on Luria-Bertani plates supplemented with $1 \%$ skim milk, Van Niel medium containing $1.5 \%$ carboxymethyl cellulose, basal agar medium containing $1 \%$ Tween 80 , and $2 \%$ agar medium containing $0.5 \%$ colloidal chitin, respectively. $c y s H$, the $c y s H$ mutant; $d g c$, the $d g c$ mutant; $p h$, the $p h$ mutant; tetR1 and tetR2, the tetR1 and tetR2 mutants; virB10, the virB10 mutant; WT, wild type L. enzymogenes strain C3; yqfA, the yqfA mutant. 
its target gene promoter (Tao et al. 2010). Considering the similarity of the $c l p$ and $r p f$ gene cluster between $X$. campestris and L. enzymogenes, c-di-GMP signaling has been reported to play an important role in L. enzymogenes (Chen et al. 2017). In L. enzymogenes, the intracellular concentration of c-di-GMP increased in the pilG mutant, which was defective in HSAF production (Chen et al. 2017). The diguanylate cyclases synthesize c-di-GMP, whereas the phosphodiesterases degrade c-di-GMP (Jenal and Malone 2006). Interestingly, mutation of a diguanylate cyclase $(d g c)$ gene resulted in loss of antifungal activity and HSAF
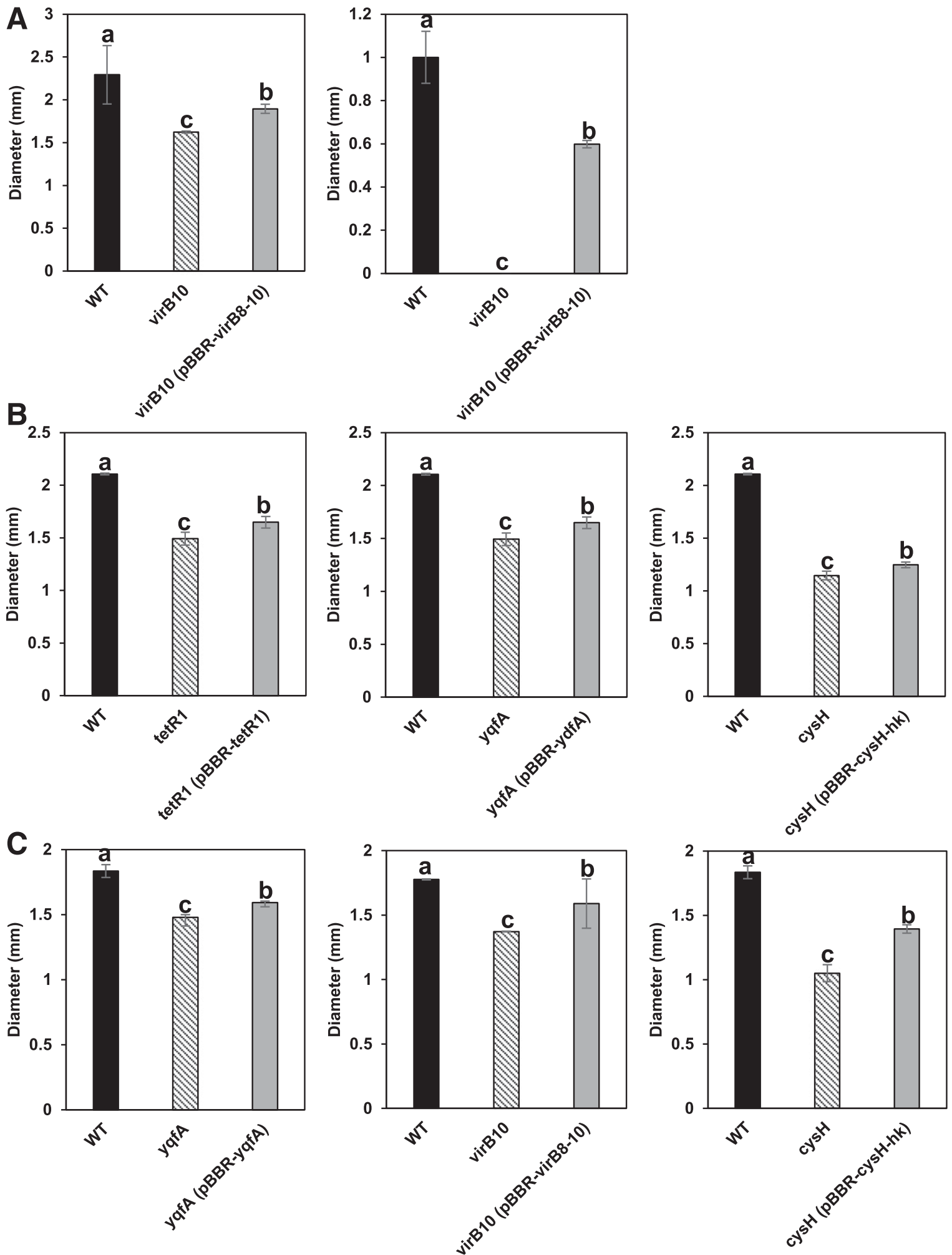

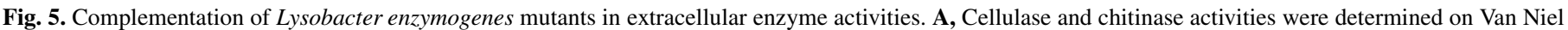

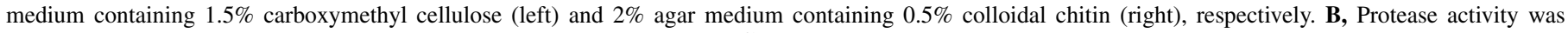

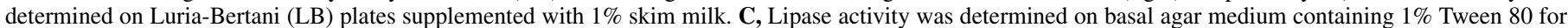

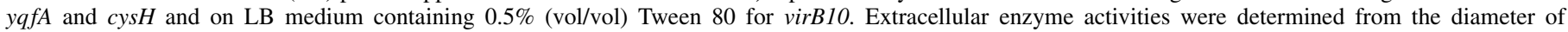

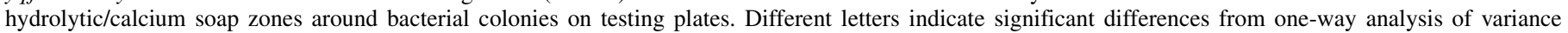

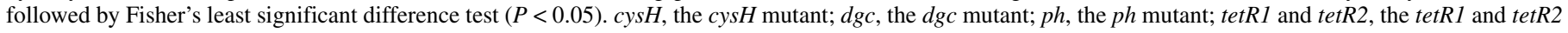
mutants; virB10, the virB10 mutant; WT, wild type L. enzymogenes strain C3; yqfA, the yqfA mutant. 
production, as well as reduced extracellular enzyme activities. These results suggest that c-di-GMP played a positive role in HSAF biosynthesis and extracellular enzyme production.

Survival of bacteria under various environments requires a multitude of rapid and adaptive responses triggered by regulatory proteins, which in most cases are transcriptional factors (TFs) (Ramos et al. 2005). Previous studies showed that LetR, a TetRfamily TF in L. enzymogenes, bound to the promoter of HSAF biosynthesis operon and suppressed HSAF biosynthesis (Ramos et al. 2005; Wang et al. 2017). In this study, we identified two TetR family TFs, and both the tetR 1 and tetR 2 mutants showed decreased HSAF production, suggesting a positive effect on HSAF production. It is possible that different TetR family TFs may play different roles in regulation of HSAF production.

Phenol hydroxylase is predicted to be a ferredoxin-NADP reductase. This reductase is a flavin adenine dinucleotide-containing enzyme that catalyzes the reversible electron transfer between NADPH and electron carrier proteins (i.e., ferredoxin and flavodoxin) (Nogués et al. 2005). The C-terminal domain contains most of the NADPH binding residues, whereas the $\mathrm{N}$-terminal domain interacts noncovalently with the isoalloxazine rings of the flavin molecule. Ferredoxin-NADP ${ }^{+}$reductase first accepts one electron from reduced ferredoxin to form a flavin semiquinone intermediate. The enzyme then accepts a second electron to form $\mathrm{FADH}_{2}$, which then transfers two electrons and a proton to $\mathrm{NADP}^{+}$to form NADPH. Isoforms of these flavoproteins in bacteria participate in a wide variety of redox metabolic pathways (Nogués et al. 2005). In this study, deletion of the $p h$ gene led to loss of activity against $S$. sclerotiorum and $F$. virguliforme, reducing extracellular enzyme activities and HSAF production. These results suggest that changes in redox-related metabolic pathways might lead to the loss of biocontrol activities in LeC3.

Members of the hemolysin III family are integral membrane proteins. In Bacillus cereus, hemolysis resulting in 3- to 3.5-nm hemolytic pores occurred in at least three steps: binding of Hyl-III monomers to the erythrocyte membrane, formation of transmembrane oligomeric pore, and erythrocyte lysis (Baida and Kuzmin 1996). The channel forming protein YqfA is predicted to participate in intracellular trafficking, secretion, and vesicular transport. Outer membrane vesicles (OMVs) produced by LeC3

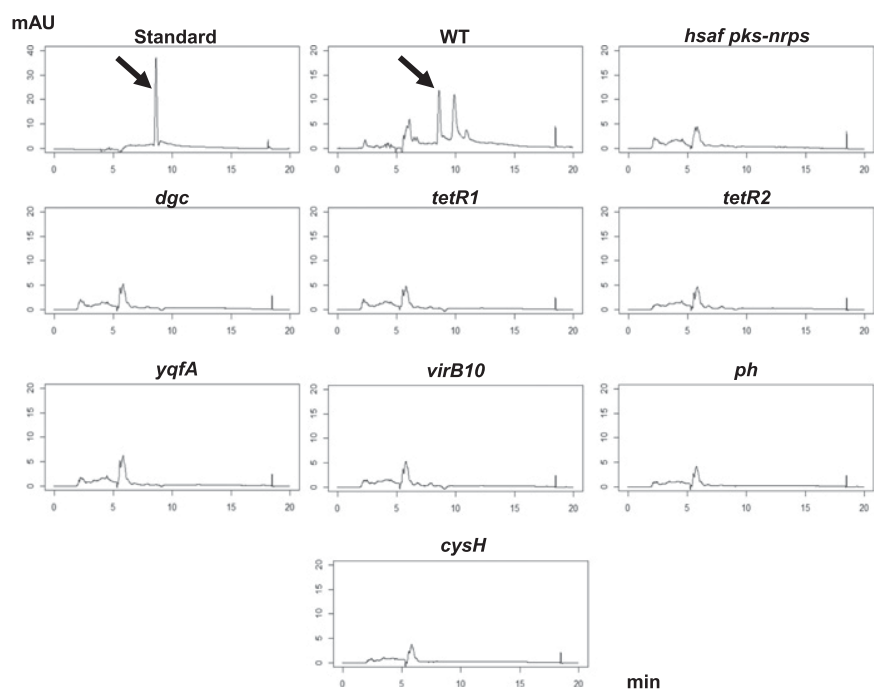

Fig. 6. Production of heat-stable antifungal factor (HSAF) in Lysobacter enzymogenes and mutant strains. Standard HSAF, Lysobacter enzymogenes strain C3 (LeC3), and the HSAF-deficient hsaf pks-nrps mutant were used as positive and negative controls. The single HSAF peak (marked by arrows) was detected by high-performance liquid chromatography in HSAF standard and LeC3 but not in the hsaf pks-nrps mutant or the seven selected mutants. cys $H$, the $c y s H$ mutant; $d g c$, the $d g c$ mutant; $p h$, the $p h$ mutant; tetR 1 and tetR2, the tetR1 and tetR2 mutants; virB10, the virB10 mutant; WT, wild type L. enzymogenes strain $\mathrm{C} 3$; $y q f A$, the $y q f A$ mutant. were discovered to contain chitinase and HSAF activities, suggesting that OMVs acted as remote mobile component of predation by LeC3 (Meers et al. 2018). This finding is consistent with our results that loss of YqfA function led to loss of extracellular enzyme and HSAF activities. It is reasonable to predict that YqfA affected biocontrol activity through its influence on OMV production, which warrants further investigation.

In summary, we identified and characterized several novel genes in suppressing soybean fungal hypha growth and spore germination and provided new information about the complex interaction between LeC3 and soybean pathogens at the molecular level. However, detailed characterization of these genes and understanding of their exact roles in extracellular enzymes and HSAF production and secretion in L. enzymogenes are needed.

\section{ACKNOWLEDGMENTS}

We thank Gary Yuan from the University of Nebraska for providing the LeC3 strain.

\section{LITERATURE CITED}

Agrios, G. N. 2005. Plant Pathology. 5th ed. Department of Plant Pathology, University of Florida, Gainesville, FL.

Ainsworth, E. A., Yendrek, C. R., Skoneczka, J. A., and Long, S. P. 2012. Accelerating yield potential in soybean: Potential targets for biotechnological improvement. Plant Cell Environ. 35:38-52.

Andersen, H., Vingaard, A., Rasmusse, T., Gjerdmansen, I., and Bonefeld-Jorgensen, E. 2002. Effects of currently used pesticides in assays for estrogenicity and aromatase activity in vitro. Toxicol. Appl. Pharmacol. 179:1-12.

Baida, G. E., and Kuzmin, N. P. 1996. Mechanism of action of hemolysin III from Bacillus cereus. BBA-Biomembranes 1284:122-124.

Brent, K. J., and Hollomon, D. W. 1998. Fungicide resistance: The assessment of risk. Global Crop Protection Federation, Brussels, Belgium.

Chen, J., Moore, W., Yuen, G., Kobayashi, D., and Caswell-Chen, E. 2006. Influence of Lysobacter enzymogenes strain C3 on nematodes. J. Nematol. 38:233-239.

Chen, J., Shen, D., Odhiambo, B. O., Xu, D., Han, S., Chou, S.-H., and Qian, G. 2018. Two direct gene targets contribute to Clp-dependent regulation of type IV pilus-mediated twitching motility in Lysobacter enzymogenes OH11. Appl. Microbiol. Biotechnol. 102:7509-7519.

Chen, Y., Xia, J., Su, Z., Xu, G., Gomelsky, M., Qian, G., and Liu, F. 2017. Lysobacter PilR, the regulator of type IV pilus synthesis, controls antifungal antibiotic production via a cyclic di-GMP pathway. Appl. Environ. Microbiol. 83:e03397-16.

Christensen, P., and Cook, F. 1978. Lysobacter, a new genus of nonfruiting, gliding bacteria with a high base ratio. Int. J. Syst. Evol. Microbiol. 28:367-393.

Clavijo, R. I., Loui, C., Andersen, G. L., Riley, L. W., and Lu, S. 2006. Identification of genes associated with survival of Salmonella enterica serovar Enteritidis in chicken egg albumen. Appl. Environ. Microbiol. 72: 1055-1064.

Costa, T. R., Felisberto-Rodrigues, C., Meir, A., Prevost, M. S., Redzej, A., Trokter, M., and Waksman, G. 2015. Secretion systems in Gram-negative bacteria: structural and mechanistic insights. Nat. Rev. Microbiol. 13: 343-359.

Mueller, D., Wise, K., Sisson, A., Smith, D., Sikora, E., Bradley, C., and Robertson, A. 2016. A Farmer's Guide to Soybean Diseases. American Phytopathological Society, St. Paul, MN.

de Bruijn, I., Cheng, X., de Jager, V., Expósito, R. G., Watrous, J., Patel, N., Postma, J., Dorrestein, P. C., Kobayashi, D., and Raaijmakers, J. M. 2015. Comparative genomics and metabolic profiling of the genus Lysobacter. BMC Genomics 16:991.

Ducey, T. F., and Dyer, D. W. 2002. Rapid identification of EZ: $\mathrm{TN}^{\mathrm{TM}}$ transposon insertion sites in the genome of Neisseria gonorrhoeae. Pages 6-7 in: Epicentre Forum. https://pdfs.semanticscholar.org/3270/ 75b8d8e525874949369bf04a434dd85e8727.pdf

Folman, L. B., Postma, J., and van Veen, J. A. 2003. Characterisation of Lysobacter enzymogenes (Christensen and Cook 1978) strain $3.1 \mathrm{~T} 8$, a powerful antagonist of fungal diseases of cucumber. Microbiol. Res. 158:107-115.

Fronzes, R., Christie, P. J., and Waksman, G. 2009. The structural biology of type IV secretion systems. Nat. Rev. Microbiol. 7:703-714.

Giesler, L. J., and Yuen, G. Y. 1998. Evaluation of Stenotrophomonas maltophilia strain C3 for biocontrol of brown patch disease. Crop Prot. 17:509-513.

Han, Y., Wang, Y., Tombosa, S., Wright, S., Huffman, J., Yuen, G., Qian, G., Liu, F., Shen, Y., and Du, L. 2015. Identification of a small molecule 
signaling factor that regulates the biosynthesis of the antifungal polycyclic tetramate macrolactam HSAF in Lysobacter enzymogenes. Appl. Microbiol. Biotechnol. 99:801-811.

Hartman, E. A., Belden, J. B., Smith, L. M., and McMurry, S. T. 2014. Chronic effects of strobilurin fungicides on development, growth, and mortality of larval Great Plains toads (Bufo cognatus). Ecotoxicology 23:396-403.

Hartman, G., Chang, H.-X., and Leandro, L. 2015. Research advances and management of soybean sudden death syndrome. Crop Prot. 73:60-66.

Hayward, A. C., Fegan, N., Fegan, M., and Stirling, G. 2010. Stenotrophomonas and Lysobacter: ubiquitous plant-associated gamma-proteobacteria of developing significance in applied microbiology. J. Appl. Microbiol. 108: 756-770.

Heydari, A., and Pessarakli, M. 2010. A review on biological control of fungal plant pathogens using microbial antagonists. J. Biol. Sci. 10:273-290.

Huerta-Cepas, J., Szklarczyk, D., Forslund, K., Cook, H., Heller, D., Walter, M. C., Rattei, T., Mende, D. R., Sunagawa, S., and Kuhn, M. 2015. eggNOG 4.5: a hierarchical orthology framework with improved functional annotations for eukaryotic, prokaryotic and viral sequences. Nucleic Acids Res.: D286-D293.

Jenal, U., and Malone, J. 2006. Mechanisms of cyclic-di-GMP signaling in bacteria. Annu. Rev. Genet. 40:385-407.

Jo, Y.-K., Won Chang, S., Boehm, M., and Jung, G. 2008. Rapid development of fungicide resistance by Sclerotinia homoeocarpa on turfgrass. Phytopathology 98:1297-1304.

Jochum, C., Osborne, L., and Yuen, G. 2006. Fusarium head blight biological control with Lysobacter enzymogenes strain C3. Biol. Control 39:336-344.

Kobayashi, D. Y., and Nour, E.-H. 1996. Selection of bacterial antagonists using enrichment cultures for the control of summer patch disease in Kentucky bluegrass. Curr. Microbiol. 32:106-110.

Kobayashi, D. Y., Reedy, R. M., Palumbo, J. D., Zhou, J.-M., and Yuen, G. Y. 2005. A clp gene homologue belonging to the Crp gene family globally regulates lytic enzyme production, antimicrobial activity, and biological control activity expressed by Lysobacter enzymogenes strain C3. Appl. Environ. Microbiol. 71:261-269.

Koenning, S. R., and Wrather, J. A. 2010. Suppression of soybean yield potential in the continental United States by plant diseases from 2006 to 2009. Plant Health Prog. doi:10.1094/PHP-2010-1122-01-RS

Kovach, M. E., Elzer, P. H., Hill, D. S., Robertson, G. T., Farris, M. A., Roop, R. M., and Peterson, K. M. 1995. Four new derivatives of the broad-hostrange cloning vector $\mathrm{pBBR} 1 \mathrm{MCS}$, carrying different antibiotic-resistance cassettes. Gene 166:175-176.

Lee, J. H., Ancona, V., and Zhao, Y. 2018. Lon protease modulates virulence traits in Erwinia amylovora by direct monitoring of major regulators and indirectly through the Rcs and Gac-Csr regulatory systems. Mol. Plant Pathol. 19:827-840.

Longo, F., Motta, S., Mauri, P., Landini, P., and Rossi, E. 2016. Interplay of the modified nucleotide phosphoadenosine 5'-phosphosulfate (PAPS) with global regulatory proteins in Escherichia coli: modulation of cyclic AMP (cAMP)-dependent gene expression and interaction with the HupA regulatory protein. Chem. Biol. Interact. 259:39-47.

Lou, L., Qian, G., Xie, Y., Hang, J., Chen, H., Zaleta-Rivera, K., Li, Y., Shen, Y., Dussault, P. H., and Liu, F. 2011. Biosynthesis of HSAF, a tetramic acidcontaining macrolactam from Lysobacter enzymogenes. J. Am. Chem. Soc. 133:643-645.

Martínez-Toledo, M., Salmeron, V., Rodelas, B., Pozo, C., and Gonzalez-Lopez, J. 1998. Effects of the fungicide Captan on some functional groups of soil microflora. Appl. Soil Ecol. 7:245-255.

Meers, P., Liu, C., Chen, R., Bartos, W., Davis, J., Dziedzic, N., Orciuolo, J., Kutyla, S., Pozo, M. J., and Mithrananda, D. 2018. Vesicular delivery of the antifungal antibiotics of Lysobacter enzymogenes C3. bioRxiv: 344838.

Narayanasamy, P. 2013. Biological Management of Diseases of Crops. Springer, Berlin, Germany.

Nian, J. L. 2015. Evaluation of Lysobacter enzymogenes C3 for control of soybean fungal diseases. http://hdl.handle.net/2142/89235

Nogués, I., Pérez-Dorado, I., Frago, S., Bittel, C., Mayhew, S. G., Gómez-Moreno, C., Hermoso, J. A., Medina, M., Cortez, N., and Carrillo, N. 2005. The ferredoxin-NADP $(\mathrm{H})$ reductase from Rhodobacter capsulatus: Molecular structure and catalytic mechanism. Biochemistry 44:11730-11740.

Ochoa-Acuña, H. G., Bialkowski, W., Yale, G., and Hahn, L. 2009. Toxicity of soybean rust fungicides to freshwater algae and Daphnia magna. Ecotoxicology 18:440-446.

Palumbo, J. D., Yuen, G. Y., Jochum, C. C., Tatum, K., and Kobayashi, D. Y. 2005. Mutagenesis of $\beta$-1,3-glucanase genes in Lysobacter enzymogenes strain $\mathrm{C} 3$ results in reduced biological control activity toward Bipolaris leaf spot of tall fescue and Pythium damping-off of sugar beet. Phytopathology 95:701-707.

Qian, G., Wang, Y., Liu, Y., Xu, F., He, Y.-W., Du, L., Venturi, V., Fan, J., Hu, B., and Liu, F. 2013. Lysobacter enzymogenes uses two distinct cell-cell signaling systems for differential regulation of secondary metabolite biosynthesis and colony morphology. Appl. Environ. Microbiol. 79:6604-6616.

Qian, G., Wang, Y., Qian, D., Fan, J., Hu, B., and Liu, F. 2012. Selection of available suicide vectors for gene mutagenesis using chiA (a chitinase encoding gene) as a new reporter and primary functional analysis of chiA in Lysobacter enzymogenes strain OH11. World J. Microbiol. Biotechnol. 28:549-557.

Qian, G., Xu, F., Venturi, V., Du, L., and Liu, F. 2014. Roles of a solo LuxR in the biological control agent Lysobacter enzymogenes strain OH11. Phytopathology 104:224-231.

Qian, G.-L., Hu, B.-S., Jiang, Y.-H., and Liu, F.-Q. 2009. Identification and characterization of Lysobacter enzymogenes as a biological control agent against some fungal pathogens. Agric. Sci. China 8:68-75.

Ramos, J. L., Martínez-Bueno, M., Molina-Henares, A. J., Terán, W., Watanabe, K., Zhang, X., Gallegos, M. T., Brennan, R., and Tobes, R. 2005. The TetR family of transcriptional repressors. Microbiol. Mol. Biol. Rev. 69:326-356.

Reichenbach, H. 2006. The genus Lysobacter. Pages 939-957 in: The Prokaryotes. Springer, Berlin, Germany.

Roberts, W. K., and Selitrennikoff, C. P. 1988. Plant and bacterial chitinases differ in antifungal activity. Microbiology 134:169-176.

Rossi, E., Motta, S., Mauri, P., and Landini, P. 2014. Sulfate assimilation pathway intermediate phosphoadenosine 5 '-phosphosulfate acts as a signal molecule affecting production of curli fibres in Escherichia coli. Microbiology 160:1832-1844.

Smith, E., and Boland, G. 1989. A reliable method for the production and maintenance of germinated sclerotia of Sclerotinia sclerotiorum. Can. J. Plant Pathol. 11:45-48.

Su, Z., Chen, H., Wang, P., Tombosa, S., Du, L., Han, Y., Shen, Y., Qian, G., and Liu, F. 2017. 4-Hydroxybenzoic acid is a diffusible factor that connects metabolic shikimate pathway to the biosynthesis of a unique antifungal metabolite in Lysobacter enzymogenes. Mol. Microbiol. 104:163-178.

Sullivan, R., Holtman, M., Zylstra, G., White, J., Jr., and Kobayashi, D. 2003. Taxonomic positioning of two biological control agents for plant diseases as Lysobacter enzymogenes based on phylogenetic analysis of 16S rDNA, fatty acid composition and phenotypic characteristics. J. Appl. Microbiol. 94: 1079-1086.

Tao, F., He, Y.-W., Wu, D.-H., Swarup, S., and Zhang, L.-H. 2010. The cyclic nucleotide monophosphate domain of Xanthomonas campestris global regulator Clp defines a new class of cyclic di-GMP effectors. J. Bacteriol. 192:1020-1029.

Taxvig, C., Hass, U., Axelstad, M., Dalgaard, M., Boberg, J., Andeasen, H. R., and Vinggaard, A. M. 2007. Endocrine-disrupting activities in vivo of the fungicides tebuconazole and epoxiconazole. Toxicol. Sci. 100:464-473.

Tigerstrom, R. G. 1980. Extracellular nucleases of Lysobacter enzymogenes: production of the enzymes and purification and characterization of an endonuclease. Can. J. Microbiol. 26:1029-1037.

Wang, P., Chen, H., Qian, G., and Liu, F. 2017. LetR is a TetR family transcription factor from Lysobacter controlling antifungal antibiotic biosynthesis. Appl. Microbiol. Biotechnol. 101:3273-3282.

Wang, Y., Qian, G., Li, Y., Wang, Y., Wang, Y., Wright, S., Li, Y., Shen, Y., Liu, F., and Du, L. 2013. Biosynthetic mechanism for sunscreens of the biocontrol agent Lysobacter enzymogenes. PLoS One 8:e66633.

Ward, W. O., Delker, D. A., Hester, S. D. Thai, S.-F., Wolf, D. C., Allen, J. W., and Nesnow, S. 2006. Transcriptional profiles in liver from mice treated with hepatotumorigenic and nonhepatotumorigenic triazole conazole fungicides: propiconazole, triadimefon, and myclobutanil. Toxicol. Pathol. 34:863-878.

Whipps, J. M. 2001. Microbial interactions and biocontrol in the rhizosphere. J. Exp. Bot.: 487-511.

Xia, Z., Zhang, W., Lei, L., Liu, X., and Wei, H.-L. 2015. Genome-wide investigation of the genes involved in nicotine metabolism in Pseudomonas putida $\mathrm{J} 5$ by Tn5 transposon mutagenesis. Appl. Microbiol. Biotechnol. 99: 6503-6514.

Yu, F., Zaleta-Rivera, K., Zhu, X., Huffman, J., Millet, J. C., Harris, S. D., Yuen, G., Li, X.-C., and Du, L. 2006. Structure and biosynthesis of heatstable antifungal factor (HSAF), a broad-spectrum antimycotic with a novel mode of action. Antimicrob. Agents Ch. 51:64-72.

Yu, M., and Zhao, Y. F. 2019. Comparative resistomic analyses of Lysobacter species with high intrinsic multidrug resistance. J. Glob. Antimicrob. Resist. 19:320-327.

Yuen, G., Steadman, J., Lindgren, D., Schaff, D., and Jochum, C. 2001. Bean rust biological control using bacterial agents. Crop Prot. 20:395-402.

Zhang, W., Li, Y., Qian, G., Wang, Y., Chen, H., Li, Y.-Z., Liu, F., Shen, Y., and Du, L. 2011. Identification and characterization of the anti-methicillinresistant Staphylococcus aureus WAP-8294A2 biosynthetic gene cluster from Lysobacter enzymogenes OH11. Antimicrob. Agents Ch. 55:5581-5589.

Zhang, Z., and Yuen, G. 1999. Biological control of Bipolaris sorokiniana on tall fescue by Stenotrophomonas maltophilia strain C3. Phytopathology 89: 817-822. 